Waste and Resource Management Volume 167 Issue WR3

A case study of the D4R laptop Hickey, Fitzpatrick, Maher et al.
Proceedings of the Institution of Civil Engineers Waste and Resource Management 167 August 2014 Issue WR3 Pages 101-108 http://dx.doi.org/10.1680/warm.13.00031 Paper 1300031

Received 24/09/2013_Accepted 02/05/2014

Keywords: energy conservation/research \&development/ sustainability ice

Institution of Civil Engineers

\title{
A case study of the D4R laptop
}

1 Stewart Hickey PhD, MBA Research Fellow, Electronic and Computer Engineering Department, University of Limerick, Limerick, Ireland

2. Colin Fitzpatrick $P h D$

Lecturer, Electronic and Computer Engineering Department, University of Limerick, Limerick, Ireland

3. Paul Maher

Managing Director, MicroPro Computers, Dublin, Ireland

4 Jose Ospina $\mathrm{MA}(\mathrm{Arch})$

Development Consultant, MicroPro Computers, Dublin, Ireland

5 Karsten Schischke Dipl.-Ing.

Senior Researcher, Technische Universität/Fraunhofer IZM, Berlin, Germany
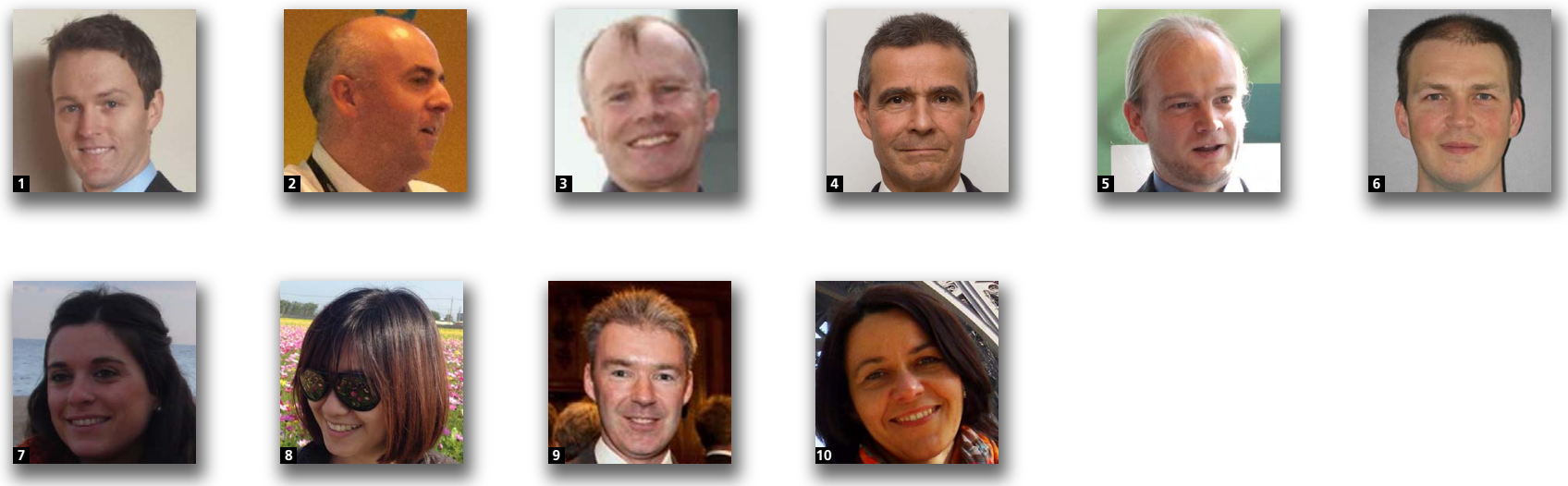

6 Peter Beigl MSc, Dipl.-Ing. Mag

Research Assistant, Institute of Waste Management, University of Natural Resources and Applied Life Sciences, Vienna, Austria

7 Itziar Vidorreta BSC, MEng

Project Manager, Gaia, San Sebastián, Spain

8 Mona Yang BA, MEM

Senior Engineer, AU Optronics Corporation, Hsinchu, Taiwan

g Ian D. Williams PhD, CChem

Professor and Head of the Centre for Environmental Sciences, Faculty of Engineering and the Environment, University of Southampton, Southampton, UK

10 Emilia den Boer Dr Inz.

Assistant Professor, Institute of Environment Protection Engineering, Wroclaw University of Technology, Wroclaw, Poland

The D4R (Design for recycling, repair, refurbishment and reuse) laptop was developed in conjunction with MicroPro Computers (MPC), a Dublin-based computer manufacturer. MPC formed an industrial network with end-of-life information technology (IT) asset management firms, IT refurbishers, component manufacturers and local industries to produce a new design that has created a new use for their wastes, thus turning waste into resources. This has been made possible through: D4R product design features that facilitate integration of by-product materials and components into the manufacturing process; the creation of an industrial network of suppliers and local assembly agencies permitting industrial metabolism of by-product materials and components into state-of-the-art laptop products; and the creation of a resource exchange platform that increases the visibility of by-products to be incorporated in newly manufactured systems. MPC has been able to successfully manufacture a universal shell composed of a motherboard and a six-cell lithium battery, encapsulated in a wooden housing structure. The shell is capable of accepting new laptop system components and also has the ability to integrate various diverse parts and components, and parts and components of different specifications. The proposed manufacturing model illustrates an entirely novel approach to industrial networking in computer manufacturing for the purpose of eliminating waste and creating valuable by-products.

\section{Introduction}

Consumerism and the trend of shortening lifecycles for electronic products in particular have increased the worldwide disposal of waste electrical and electronic equipment (WEEE) (Ongondo et al.,
2011). With an estimated 40-50 Mt of WEEE generated annually worldwide (Guan et al., 2007; Schluep et al., 2009), this creates a host of sustainability challenges for the electronics industry and the growing number of industries that depend on electronics. 
Many governments around the world have adopted environmental policies to enhance lifecycle thinking and preventative measures for WEEE (Atasu and van Wassenhove, 2012; Tojo, 2004). One such policy in the European Union (EU) is the WEEE directive 2002/96/EC (EC, 2003). However, despite the comprehensive regulations regarding WEEE in the EU, it is estimated that only $25-40 \%$ is treated formally with the rest either remaining in long-term storage or going to landfill or illegal export (UNU, 2008). Many unscrupulous operators export WEEE illegally as this is more profitable than recycling it through formal channels (UNU, 2008; Widmer et al., 2005). Assuming equipment does make it into the formal WEEE management channels, the material is often sent for recycling, which is energy intensive and does not recover many of the valuable critical materials in electronics (Chancerel et al., 2009; Epstein and Yuthas, 2011; UNEP, 2011).

Design for recycling, repair, refurbishment and reuse, or D4R, is one design strategy that focuses on reducing impacts at endof-life (EoL). The associated design measures allow intervention at 'first EoL' to bring back a product into a second lifecycle and postpone the time when a product ultimately reaches its EoL (Marwede et al., 2011). The D4R concept serves to mitigate environmental impacts incurred in manufacturing and conserve critical resources required for production of equipment by keeping products or components in use for a longer period of time.

The case study of the D4R laptop presented here is one of ten demonstrators being investigated as part of the European Framework 7 project Zerowin (Towards zero waste in industrial networks), running from 2009 to 2014. Industrial networking focuses on a regional collaboration of companies from traditionally different sectors to exchange by-products (materials, energy, water, etc.) in such a way that the waste from one industry becomes the raw material for another. The Zerowin project has developed innovative approaches and strategies for the prevention of waste in industries based on the zero waste philosophy. Zero waste represents a shift from the traditional industrial model in which wastes are considered the norm, to integrated systems in which everything has its use (Curran and Williams, 2012).

The D4R laptop manufacturing model described in this paper was enabled through D4R measures and supply of by-product parts and materials through an industrial network. The concept involves the design of a universal motherboard that is a laptop motherboard incorporating D4R design features that facilitate integration of by-product computer components into the manufacturing process. The motherboard is incorporated into a barebones laptop chassis, also incorporating D4R product design features that facilitate integration of by-product materials and used computer components into laptop production.
This paper investigates the considerations involved in laptop manufacturing in the context of industrial networks. The article is structured as follows. Section 2 elaborates on the development of the D4R laptop concept. Section 3 describes concept implementation in practice. Section 4 discusses the economic, technological and market barriers impeding successful implementation of the concept. Finally, Section 5 presents a summary and outlook.

\section{Concept development}

\subsection{Background}

For computer systems, a strong case has been made in the academic literature for eco-design to facilitate lifetime extension of the primary electronics parts (Hickey et al., 2009; Truttmann and Rechberger, 2006; Williams, 2011). This stems from the knowledge that the energy and carbon footprint for manufacturing can often exceed that associated with usage. For example, the product carbon footprint of a mainstream laptop encompassing raw materials consumption, manufacturing, logistics, product use and EoL management was determined to be $300-400 \mathrm{~kg}$ carbon dioxide equivalents; of this figure, $150 \mathrm{~kg}$ was deemed attributable to the manufacturing phase alone (Stutz and Moriarty, 2010). Another analysis carried out on a separate laptop computer in 2012 estimated that $214 \mathrm{~kg}$ of carbon dioxide equivalents arise from production and $138 \mathrm{~kg}$ from 5 years of use (Prakash, 2011). From these examples, it is clear that any strategy involving the use of industrial networks to achieve the Zerowin vision in the context of laptop manufacturing must involve design to facilitate primary computer component reuse.

\subsection{D4R concept}

The proposed concept is in line with the European waste management hierarchy, which places reuse as the highest priority. The Dublin-based computer manufacturer MicroPro Computers (MPC) formed an industrial network with EoL information technology (IT) asset management firms, IT refurbishers and other local industries to produce a new design that creates a new use for their wastes, thus turning wastes into by-products. The industrial network is shown in Figure 1.

The focal point of the network is a barebones laptop that consists of a chassis, a universal motherboard and a battery, around which the D4R laptop is built. The laptop design is such that it is capable of accepting diverse computer parts (e.g. RAM, hard disks and processors of different specifications). The materials sourced from the industrial network to manufacture the new universal chassis include wood for the chassis itself and cardboard to be used for packaging and distribution of the final product. The liquid crystal display (LCD) screen, memory, power supply, processor, keyboard, hard drive and 


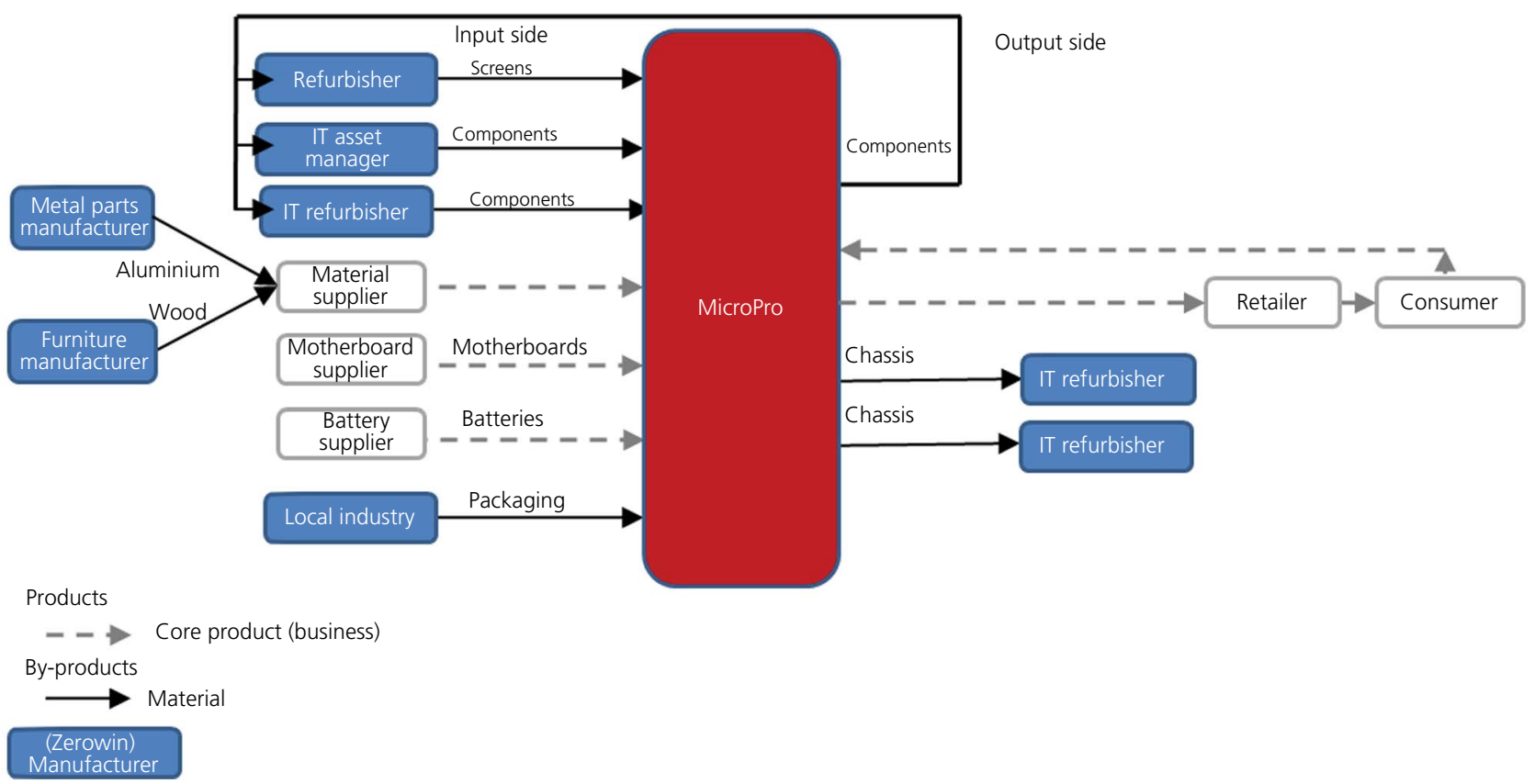

Figure 1. D4R laptop concept based on the Zerowin project vision

other peripheral cables are also sourced from the industrial network.

Fundamental to the operation of the industrial network is the use of a web-based resource exchange platform (RXP) (www. trxp.eu) to coordinate the availability and supply of byproducts for production planning. This was developed as part of a separate case study in the Zerowin project. Each member of the industrial network inputs information about the company's availability of parts, including specification and quality, and information on local marketing intelligence about demand. This exchange of information and materials within the network enables a smooth manufacturing process, sales and support services. This is also important to ensure the consistent availability of parts.

A long-term objective is to take back products from consumers and make the universal chassis available to other members of the industrial network to resell or lease in their respective jurisdictions. This additional lifetime extension of the chassis, particularly the motherboard, can facilitate greater resource and energy efficiency. This provides further incentive for MPC to incorporate $\mathrm{D} 4 \mathrm{R}$ changes to facilitate lifetime extension of systems.

\section{Implementation}

The network of companies cooperating with each other on the basis of resources exchange in the case study includes
MPC, Rehab Recycle (a Dublin-based social economy IT asset manager), ReUse Computer Network (a non-profit association of IT refurbishers based in Germany), Emaus (a computer refurbisher and assembler based in Spain's Basque region), Eguarlandua (association for the second transformation of wood in the Basque country), AU Optronics Corporation (AUO) (thinfilm transistor (TFT) LCD manufacturer, Taiwan), Geraghty Furniture (furniture manufacturer based in Galway) and some local industries (to supply materials required for packaging). Table 1 provides a list of the partners, highlighting their core business as well as their by-products stemming from their primary business activities.

The new business model, based on an industrial network, is fully operational and scalable. The materials sourced from the industrial network to manufacture the new universal chassis include used plywood (sourced from used pallets) for the cladding of the chassis and used cardboard to package and distribute the final product. The primary computer components sourced from the industrial network to populate the laptop include the LCD screen, RAM modules, the power supply, other peripheral cables, the processor, the keyboard and the hard disk drive. These by-product parts are sourced from Rehab Recycle (Ireland), the Berlin ReUse Network and Emaus/Eguarlandua (Basque partners) through the RXP.

Testing is a key part of 'triage' operations concerning electronics design to enhance reuse/recycling value (GEC, 


\begin{tabular}{lll} 
Partner & Core business & By-products $^{\mathrm{a}}$ \\
\hline ReUse Computer Network & Sale of refurbished systems & $\begin{array}{l}\text { Primary electronics components (RAM, hard disks, } \\
\text { LCD panels) }\end{array}$ \\
Rehab Recycle & Sale of refurbished systems & $\begin{array}{l}\text { Primary electronics components (RAM, hard disks, } \\
\text { LCD panels) }\end{array}$ \\
NGS and Emaus & Sale of refurbished systems & $\begin{array}{l}\text { Primary electronics components (RAM, hard disks, } \\
\text { LCD panels) }\end{array}$ \\
AUO & Sale of new LCD panels & Remanufactured LCD panels \\
Geraghty Furniture & Sale of furniture & Furniture off-cuts \\
CFTooling & Sale of industrial equipment and tools & Aluminium \\
\hline
\end{tabular}

${ }^{\mathrm{a} B y}$-products made visible through RXP for the manufacture of D4R laptop systems

Table 1. Partners in the D4R industrial network collaborating with each other on the basis of resource exchange

2008): triage operations are defined as the inventorying, sorting and as appropriate, the testing, of incoming material in order to route into the selected business activities'. The minimum basic testing standards for all used computer parts sourced from the network are detailed in Table 2. These tests ensure that by-product parts re-integrated into the manufacturing process adhere to minimum quality thresholds. It is also desirable for new industrial network partners to be certified to ISO 14001 (environmental), ISO 9001 (quality) and PAS 141:2010 (specification for the processing for reuse of waste and used electrical and electronic equipment).

The D4R laptop, composed of a universal motherboard and a six-6 cell lithium battery encapsulated in a wooden housing structure, is shown in Figure 2. The computer system was designed around a universal motherboard (Figure 3) with design for repair and upgradability in mind. The motherboard itself uses Sandy Bridge 1155 sockets and is capable of accepting a chipset that will facilitate Intel dual core i3, i5 and i7 processors. This is desirable to ensure that any shortage of specific processor types in the industrial network can be replaced by a different type from the same family of processors.
The use of wood for casing manufacture (Figure 4) enables the chassis to be easily rebuffed, returning the material surface finish to 'like new' by abrasion with sand paper. The use of wood also enables the chassis to be replaced or reworked to accommodate a change in chassis design or small variations in screen dimension.

The laptop has a $15 \cdot 6^{\prime \prime}(39 \cdot 6 \mathrm{~cm})$ TFT LCD screen as shown in Figure 5. (The largest market demand is for laptops with this particular screen dimension.) However, the laptop can also accommodate screen sizes as small as $13 \cdot 3^{\prime \prime}(33 \cdot 8 \mathrm{~cm})$ provided the front frame enclosure is substituted with one of the relevant size. This design feature promotes more reuse of screens should they become available within the industrial network.

\section{Discussion}

The proposed D4R manufacturing model can facilitate significant energy and resource savings over conventional laptop manufacture. A comparison with conventional laptop manufacturing and the results of a lifecycle assessment illustrating the magnitude of the associated environmental savings will be presented in a subsequent paper. The following

\begin{tabular}{ll}
\hline Component & Test requirements \\
\hline Memory & Stress test, burn in test, address test, math test \\
Hard drive & Blanco test, surface test, self-monitoring and reporting technology test, random seek test \\
Processor & Stress test, temperature test, address test \\
DVD drive & DVD \& CD testing, firmware update \\
Screen & AUO total quality assurance system \\
Cable & Functioning cables tested for continuity and shorts
\end{tabular}

Table 2. Minimum testing standards for used components sourced through the RXP 


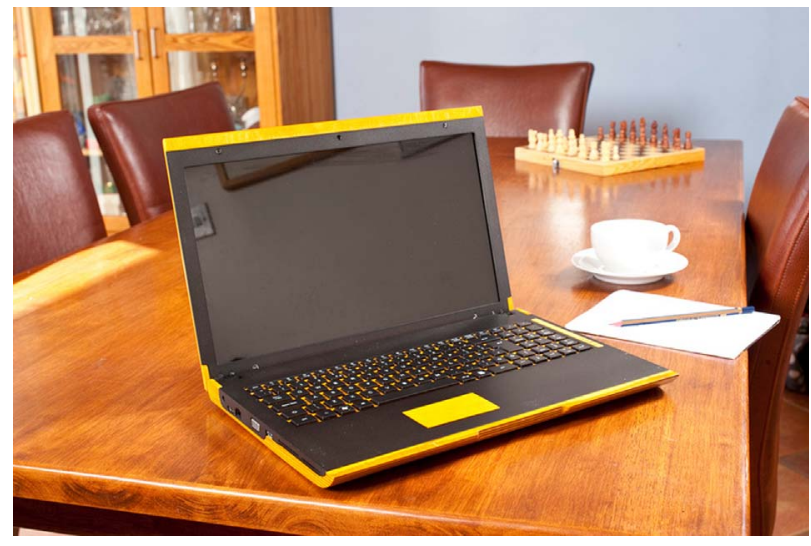

Figure 2. D4R laptop front view

paragraphs discuss the economic, technological and market barriers impeding successful implementation of the case study concept.

\subsection{Economic barriers}

The D4R network scenario proposed in this case study can only be deemed economically feasible if there is an adequate supply of quality used primary computer system components to populate the universal shell. In turn, for an adequate supply of second-generation components, there must be an adequate supply of end-of-use laptops to the industrial network partners dealing in end-of-use products. This is essentially an issue of reverse logistics -supply uncertainties in terms of quality, timing and quantity of returned products are issues that impact the feasibility of the proposed concept (Ferrer and Ayres, 2000; Ferrer and Whybark, 2003).

An efficient acquisition and reverse distribution system is essential for tracking, collection and returning used products

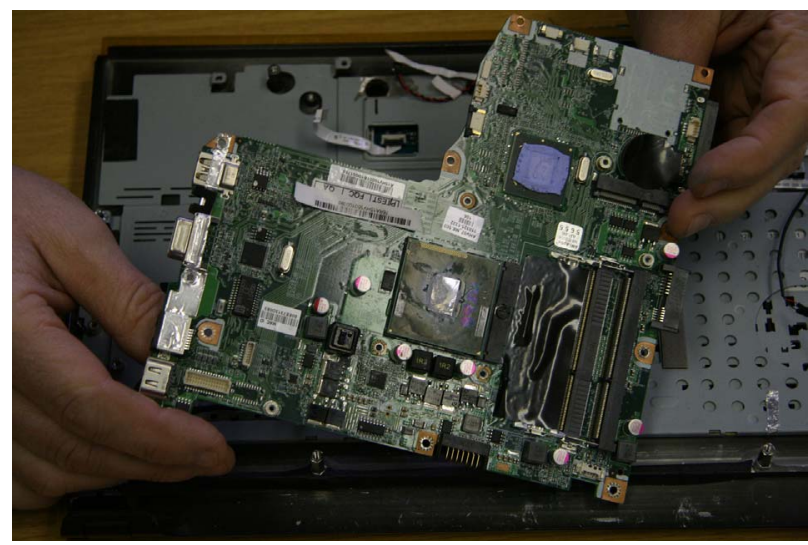

Figure 3. D4R universal motherboard

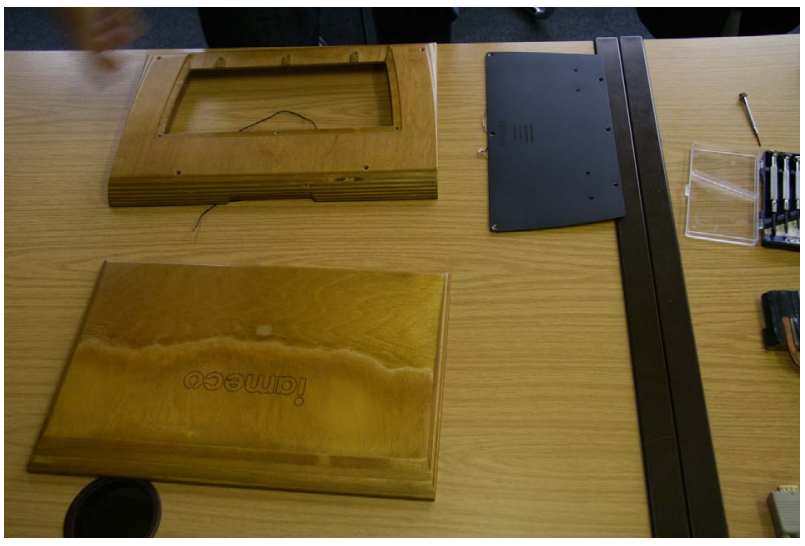

Figure 4. Casing front and back cover

to the IT asset management/refurbishment facilities. In addition, the physical distance between industrial network partners is of notable importance: the transport of by-products over long distances negatively impacts profitability, meaning that the distances to be covered need to be as short as possible. Experience from an industrial symbiosis programme in Denmark ('Kalundborg') demonstrated that geographical distance is the most important parameter when energy is exchanged between companies (Jacobsen, 2006). In this instance, however, the byproducts being exchanged are materials and components that can be transported over larger distances. Some of the partners in the programme (Rehab Recycle, Geraghty Furniture and CFTooling) are also located in Ireland, which augers well for the proposed industrial network.

The RXP developed as part of the Zerowin project aims to address the network constraint outlined previously. The objective of the exchange platform is to increase the availability of parts/components to members of the industrial network.

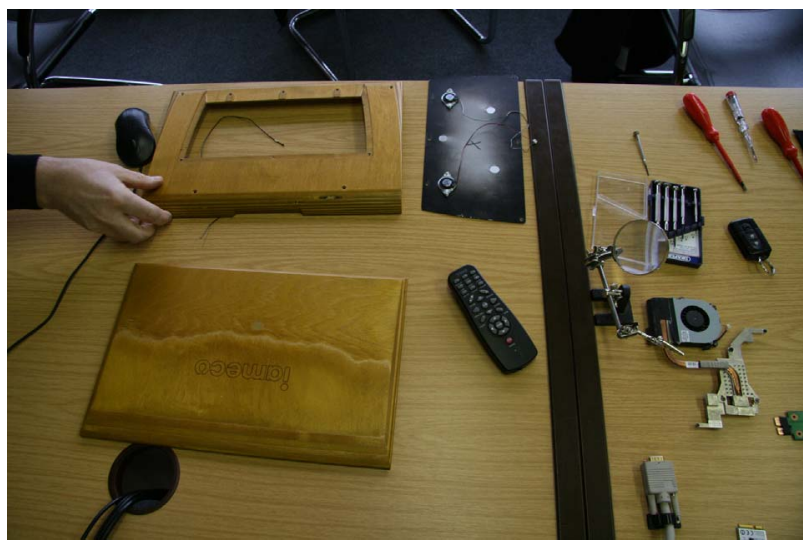

Figure 5. D4R disassembly, showing screen 
This will allow network partners to view the quality, timing and quantity volumes of primary system computer parts (or materials) in the network at any given time. Through information sharing about the specification of parts being received by the asset managers and IT refurbishers it will be possible to customise the product for different customer segments based on their technical requirements. The platform will also be an invaluable source of information regarding trends in availability of parts and will enable MPC to develop iterative versions of the universal motherboard to cope with emerging trends in IT waste. In addition, partners will also share information about market demands and trends in various locations and feedback on how the product is being received by customers in different markets. Indeed, the RXP at this early stage of the Zerowin project is starting to demonstrate is ability concerning increasing product/component availability for industrial networks, with 726 products already registered on the platform by March 2013 (Deitrich et al., 2013).

Knowing what quantities of products and materials are available and where they are available is important for the success of the proposed D4R industrial network. This is particularly important in the context of the primary laptop components potentially sourced from ReUse Computer Network in Germany and the Basque network partners (NGS and Emaus). Radio frequency identification (RFID) used in conjunction with appropriate architectural frameworks can address this issue through increasing the visibility of byproducts in industrial networks. The experimental work carried out by Hickey et al. (2012) demonstrated that RFID technology, taking a number of considerations into account, can achieve reliable EoL identification in addition to (and ultimately facilitate) brand identification for individual producer responsibility. Suitable tags and optimal transponder positions to enable reliable EoL identification for laptops, desktops and LCD products have been demonstrated through an investigation of a series of EoL use case scenarios. It was also established that the middleware technology configuration considered most appropriate for the electrical and electronic equipment sector was EPCglobal IT architecture. Furthermore, at this point in time, it would be feasible to work with a custom-made RXP as proposed within Zerowin and, once standardisation of discovery services is complete, this will pave the way for the creation of far more dynamic industrial networks that do not need such a high level of administration as the proposed RXP.

\subsection{Technological barriers}

In terms of technological barriers to industrial networking, a problem arises when assessing the quality of second-hand components. This issue arises from a lack of information associated with returned products. In terms of testing (the primary system components of EoL systems), it is clear that design changes are required to make remanufacturing and/or refurbishing viable strategies. It is true that mid- to low-end specification systems do not retain the high value core evidenced by the prices for used motherboard and primary system components. An efficient testing process is therefore imperative to ensure the success of these strategies.

MPC and its industrial partners have adopted functionality tests (Table 2) to test primary laptop parts to an acceptable level. However, this testing process is time consuming. Condition monitoring technologies are a potential solution to the realisation of efficient triage operations to promote the success of the D4R laptop concept operating at a macro-level into the future. The environmental lifecycle information management and acquisition project for consumer products (Elima) was an EC-funded research project that demonstrated the successful operation of embedded usage monitoring technologies that can serve to enhance the profitability of triage operations (Elima, 2005). An extension of the condition monitoring concept employing RFID for retrieval of lifecycle information to allow more efficient and cost-effective triage operations was demonstrated by Cronin et al. (2010). Parameters such as operating time, operating temperature, operating voltage, power cycle counts, hard disk drive self-monitoring and reporting technology attributes and operating system event information are currently attainable or derivable via embedded technologies in modern desktop systems (Hickey et al., 2009). Extraction of this lifetime usage data by way of RFID can provide an efficient cost-effective means of testing of used systems before streamlining respective system parts to the most appropriate EoL activity, be it remanufacturing, reuse or recycling.

\subsection{Market barriers}

Market barriers to the commercialisation of the D4R laptop must be overcome in order to ensure its commercial viability. The primary market barriers to the implementation of the D4R concept are as follows.

- Price. The D4R laptop cannot be produced in small numbers at a level that is competitive with commercial brands. A substantial market demand would be required to justify industrial production of the D4R.

Market identification. Given the unique characteristics of the D4R, it is likely to appeal to very specific market segments. For a commercial drive to be successful given limited resources, it is essential to identify this market segment accurately.

- Consumer confidence. The D4R must establish confidence in its potential market segments. This is related to effective marketing and branding, but also to labelling, in particular the possibility of securing appropriate labelling (e.g. the European Eco-Label). 


\section{Conclusion}

This paper has described an entirely novel approach to industrial networking in computer manufacturing for the purpose of eliminating waste and creating valuable by-products. At a product level, the universal motherboard and the barebones laptop chassis with the ability to integrate various diverse parts and components (and parts and components of different specifications) have been demonstrated as technically feasible. At a system level, the RXP can help to increase the availability of quality used components, which reduces quality, timing and quantity uncertainties. This is also important for reliable industrial network operation.

There are a few technological barriers at product level that negatively influence the feasibility of these processes. The results of this case study highlight the importance of industrial networks in supporting reuse as a strategy for the elimination of waste and the importance of eco-design and, more specifically, D4R strategies as the basis for waste elimination in industrial networks.

\section{Acknowledgement}

The research leading to these results received funding from the European Community's Seventh Framework Programme (FP7/2007-2013) under grant agreement 226752.

\section{REFERENCES}

Atasu A and Van Wassenhove L (2012) An operations perspective on product take-back legislation for e-waste: practice, trends and research needs. Production and Operations Management 21(3): 407-422.

Chancerel P, Meskers C, Hageluken C and Rotter S (2009) Assessment of precious metal flows during pre-processing of waste electrical and electronic equipment. Journal of Industrial Ecology 13(5): 791-810.

Cronin E, Hickey S and Fitzpatrick C (2010) A method for extracting historical thermal data from used PCs to foster reuse. Proceedings of IEEE International Symposium on Sustainable Systems and Technology. IEEE, Washington, DC, USA, pp. 1-5.

Curran T and Williams ID (2012) A zero waste vision for industrial networks in Europe. Journal of Hazardous Materials 207-208: 3-7.

Deitrich J, Becker F, Kopacekh B et al. (2013) Case Study 3. Concept Paper for All Networks/Pilot Applications. Deliverable 6A.3 of the project ZeroWIN, Towards zero waste in industrial networks (grant agreement number 226752).

EC (European Community) (2003) Directive 2002/96/EC of the European Parliament and of the Council of 27 January 2003 on waste electrical and electronic equipment (WEEE) Official Journal of the European Communities L037.
Elima (2005) Product lifecycle technology - results and implications for business strategy. Proceedings of Elima Seminar, Vienna, Austria.

Epstein MJ and Yuthas Y (2011) Conflict minerals: managing an emerging supply-chain problem. Environmental Quality Management 21(2): 13-25.

Ferrer G and Ayres R (2000) The impact of remanufacturing in the economy. Ecological Economics 32(3): 413-429.

Ferrer G and Whybark DC (2003) The economics of remanufacturing. In Business Aspects of Closed-loop Supply Chains (Guide VDR and van Wassenhove L (eds)). Carnegie Mellon University Press, Pittsburgh, PA, USA.

GEC (Green Electronics Council) (2008) Closing the Loop: Electronics Design to Enhance Reuse/Recycling Value. Discussion Draft Report, Green Electronics Council in collaboration with the National Center for Electronics Recycling and Resource Recycling. GEC, Portland, OR, USA.

Guan YF, Wang JZ, Luo XJ, Mai BX and Zeng EY (2007) riverine inputs of polybrominated diphenyl ethers from the Pearl River Delta (China) to the coastal ocean. Environmental Science and Technology 41(17): 6007-6013.

Hickey S, Fitzpatrick C, O'Connell M and Johnson M (2009) Use phase signals to promote lifetime extension for Windows PCs. Environmental Science and Technology 43(7): 2544 2549.

Hickey S, Fitzpatrick C, Middendorft A et al. (2012) Innovative Technologies for Individual Producer Responsibility and Product Re-use. Deliverable 2.1 of the project ZeroWIN, Towards zero waste in industrial networks (grant agreement number 226752).

Jacobsen NB (2006) Industrial symbiosis in Kalundborg, Denmark: a quantitative assessment of economic and environmental aspects. Journal of Industrial Ecology 10(1): 239-255.

Marwede M, Schischke K, Anzizu M et al. (2011) Design for recycling measures for waste prevention in high-tech sectors: the case of laptop computers and photovoltaic modules. Proceedings of 6th International Conference on Waste Management and Technology, Suzhou, China.

Ongondo FO, Williams ID and Cherrett TL (2011) How are WEEE doing? A global review of the management of electrical and electronic wastes. Waste Management 31(4): 714-730.

Prakash S (2011) Frequent Replacement of Notebooks Harms the Climate and the Environment. See http://www.oeko.de/ press/press_releases/dok/1434.php (accessed 26/03/2013).

Schluep M, Hagelüken C, Kuehr R et al. (2009). Recycling - From $e$-waste to Resources. See http://isp.unu.edu/news/2010/files/ UNEP_eW2R_publication.pdf (accessed 17/08/2013).

Stutz M and Moriarty T (2010) Product carbon footprint of a Dell laptop: results and recommendations. Proceedings of CARE Innovation, Vienna, Austria. 
Tojo N (2004) Extended Producer Responsibility as a Driver for Design Change - Utopia or Reality? Doctoral dissertation, International Institute for Industrial Environmental Economics, Lund University, Sweden.

Truttmann N and Rechberger $\mathrm{H}$ (2006) Contribution to resource conservation by reuse of electrical and electronic household appliances. Resources, Conservation and Recycling 48: 249262.

UNEP (United Nations Environment Programme) (2011)

Recycling Rates of Metals - A Status Report, A Report of the Working Group on the Global Metals Flows to the
International Resource Panel, by Graedel TE, Allwood J, Birat JP et al. UNEP, Paris, France.

UNU (United Nations University) (2008) 2008 Review of Directive 2002/96 on Waste Electrical and Electronic Equipment (WEEE). See http://ec.europa.eu/environment/waste/weee/ pdf/final_rep_unu.pdf (accessed 29/05/2014).

Widmer R, Oswald-Krapf H, Sinha-Khetriwal D, Schnellmann M and Boni H (2005) Global perspectives on e-waste. Environmental Impact Assessment Review 25(5): 436-458. Williams E (2011) Environmental effects of information and communications technologies. Nature 479(7373): 354-358.

\section{WHAT DO YOU THINK?}

To discuss this paper, please email up to 500 words to the editor at journals@ice.org.uk. Your contribution will be forwarded to the author(s) for a reply and, if considered appropriate by the editorial panel, will be published as discussion in a future issue of the journal.

Proceedings journals rely entirely on contributions sent in by civil engineering professionals, academics and students. Papers should be 2000-5000 words long (briefing papers should be 1000-2000 words long), with adequate illustrations and references. You can submit your paper online via www.icevirtuallibrary.com/content/journals, where you will also find detailed author guidelines. 